\title{
IS LOW VOLTAGE VENTRICULAR FIBRILLATION STILL A DIAGNOSTIC PROBLEM?
}

\author{
Marek Malysz $^{1}$, Piotr Kacprzak ${ }^{1}$ \\ ${ }^{1}$ Medical Simulation Center, Lazarski University, Warsaw, Poland
}

Disaster Emerg Med J 2019; 4(1): 31-32

Sir,

According to the studies by Vukmir, ventricular fibrillation accounts for nearly $45 \%$ of the rhythms initiating cardiac arrest [1]. Rapid interpretation of ECG and the implementation of appropriate management determines the effectiveness of cardiopulmonary resuscitation $[2,3]$. In the case of ventricular fibrillation, both the American Heart Association (AHA) and the European Resuscitation Council (ERC) guidelines recommend defibrillation as soon as possible [4]. Low-voltage ventricular fibrillation may be problematic. If there is any doubt as to whether an ECG record shows asystole or low-voltage VF, the guidelines do not recommend defibrillation, but the chest compression and ventilation that should be continued instead. ERC Resuscitation guidelines 2010 in the case of low-voltage ventricular fibrillation in order to differentiate the rhythm with the asystole, indicated the need for a confirmation protocol of the asystole which included both the change of the leads and increases in the amplitude of ECG and checking the wiring. In most cases, this procedure resulted in a distinction between VF and asystole [5]. At present, the guidelines only recommend changing the leads, which may interfere with the interpretation of the rhythm in the case of low-voltage ventricular fibrillation [6].

The aim of the study was to evaluate the management of nurses in case of cardiac arrest in the rhythm of fine ventricular fibrillation under conditions of simulated cardiopulmonary resuscitation. The study involved 46 nurses who participated in the Advances Cardiovascular Life Support (ACLS) course. The participants performed 10-minute cardiopulmo- nary resuscitation as the leaders of the resuscitation team. Cardiopulmonary resuscitation was based on a low-voltage and high-voltage ventricular fibrillation scenario (Fig. 1). Both the order of participants and research methods were random. The coin flipping technique was used for this purpose.

The median age of study participants was 45 years $(I Q R ; 31-50)$ and the median length of service was 23.5 years (IQR; 12-29.5). The protocol of confirmation of the asystole was done with the first interpretation of the rhythm by 6 participants, which constituted $13 \%$ of the research group. In the case of the second rhythm analysis after 2 minutes of resuscitation, the asystole confirmation protocol was performed by $36.9 \%$ of the subjects. If ventricular fibrillation was confirmed, defibrillation was performed.

Failure to perform the protocol and to interpret the rhythm as low-voltage ventricular fibrillation resulted in a lack of defibrillation. Early defibrillation is the major key to a successful outcome, according to the studies by Krittayaphong [7]. In turn, delayed defibrillation is associated with lower rates of survival after cardiac arrest [8].

According to the study, nurses occasionally perform an asystole confirmation protocol, which in the conditions of real resuscitation may delay the defibrillation in low-voltage ventricular fibrillation and thus adversely affect the patient's prognosis with cardiac arrest. However, according to Kurowski et al. studies, a short training in ECG interpretation allows for correct interpretation of ECG [9]. To sum up, ECG interpretation training should be implemented among nurses, which will also place great 


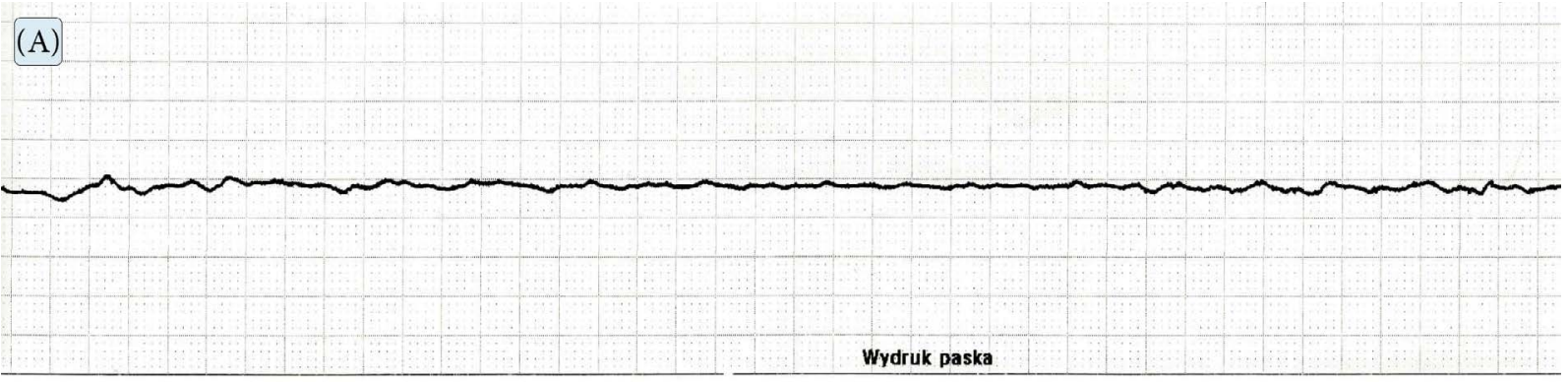

?(B) późnienie Wstrzym. dźwi ệku al. Dorosły HR 132 u/mirniem/dziec

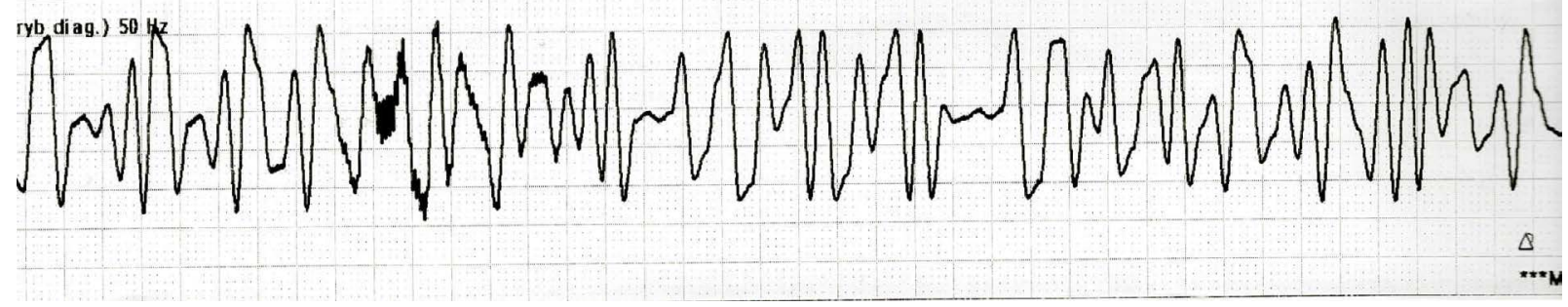

FIGURE 1. Ventricular Fibrillation: (A) Low Voltage; (B) High-voltage.

emphasis on the implementation of the full asystole recognition protocol.

\section{REFERENCES}

1. Vukmir RB. Initial cardiac rhythm correlated to emergency department survival. Clin Med Cardiol. 2009; 3: 9-14, indexed in Pubmed: 20508762.

2. Mysiak A, Kobusiak-Prokopowicz M, Kaaz K, et al. Characteristics of chaotic processes in electrocardiographically identified ventricular arrhythmia. Cardiol J. 2017; 24(2): 151-158, doi: 10.5603/ CJ.a2016.0088, indexed in Pubmed: 27734459.

3. Telecka-Gądek D, Madziała M, Szarpak Ł, et al. Acute coronary syndromes in the practice of the emergency medical team. Disaster and Emergency Medicine Journal. 2018; 3(2): 61-66, doi: 10.5603/demj.2018.0014.

4. Link MS, Berkow LC, Kudenchuk PJ, et al. Part 7: Adult Advanced Cardiovascular Life Support: 2015 American Heart Association Guidelines Update for Cardiopulmonary Resuscitation and Emergency Cardiovascular Care. Circulation. 2015; 132(18 Suppl 2): S444-S464, doi: 10.1161/CIR.0000000000000261, indexed in Pubmed: 26472995.
5. Kurowski A, Smereka J, Szarpak L. Are firefighters able to recognize ventricular fibrillation? Preliminary data. Am J Emerg Med. 2016; 34(9): 1885-1886, doi: 10.1016/j.ajem.2016.06.050, indexed in Pubmed: 27358043.

6. Abelsson A, Lundberg L. Prehospital CPR training performed with visual feedback. Disaster and Emergency Medicine Journal. 2018; 3(2): 41-45, doi: 10.5603/demj.2018.0010.

7. Krittayaphong R, Saengsung P, Chawaruechai T, et al. Early defibrillation: a key for successful outcome of in-hospital cardiac arrest. J Med Assoc Thai. 2009; 92 Suppl 2: S1-S5, indexed in Pubmed: 19562978.

8. Chan PS, Krumholz HM, Nichol G, et al. American Heart Association National Registry of Cardiopulmonary Resuscitation Investigators. Delayed time to defibrillation after in-hospital cardiac arrest. N Engl J Med. 2008; 358(1): 9-17, doi: 10.1056/NEJMoa0706467, indexed in Pubmed: 18172170.

9. Kurowski A, Smereka J, Szarpak L. Are firefighters able to recognize ventricular fibrillation? Preliminary data. Am J Emerg Med. 2016; 34(9): 1885-1886, doi: 10.1016/j.ajem.2016.06.050, indexed in Pubmed: 27358043. 